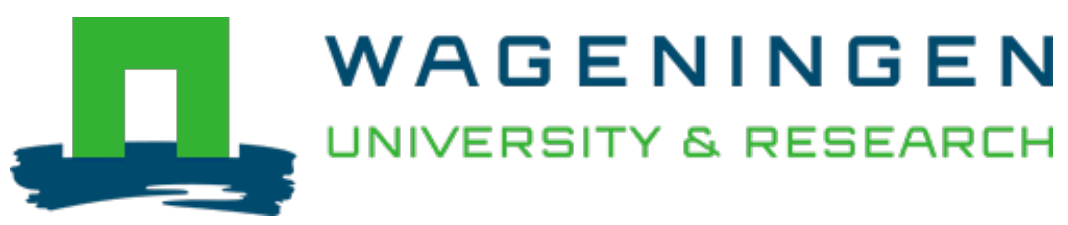

\title{
Functionality of selected strains of moulds and yeasts from Vietnamese rice wine starters
}

\author{
Food Microbiology \\ Dung, N.T.P.; Rombouts, F.M.; Nout, M.J.R. \\ https://doi.org/10.1016/j.fm.2005.05.002
}

This publication is made publicly available in the institutional repository of Wageningen University and Research, under the terms of article $25 \mathrm{fa}$ of the Dutch Copyright Act, also known as the Amendment Taverne. This has been done with explicit consent by the author.

Article 25 fa states that the author of a short scientific work funded either wholly or partially by Dutch public funds is entitled to make that work publicly available for no consideration following a reasonable period of time after the work was first published, provided that clear reference is made to the source of the first publication of the work.

This publication is distributed under The Association of Universities in the Netherlands (VSNU) 'Article $25 \mathrm{fa}$ implementation' project. In this project research outputs of researchers employed by Dutch Universities that comply with the legal requirements of Article $25 \mathrm{fa}$ of the Dutch Copyright Act are distributed online and free of cost or other barriers in institutional repositories. Research outputs are distributed six months after their first online publication in the original published version and with proper attribution to the source of the original publication.

You are permitted to download and use the publication for personal purposes. All rights remain with the author(s) and / or copyright owner(s) of this work. Any use of the publication or parts of it other than authorised under article $25 \mathrm{fa}$ of the Dutch Copyright act is prohibited. Wageningen University \& Research and the author(s) of this publication shall not be held responsible or liable for any damages resulting from your (re)use of this publication.

For questions regarding the public availability of this publication please contact openscience.library@wur.nl 


\title{
Functionality of selected strains of moulds and yeasts from Vietnamese rice wine starters
}

\author{
N.T.P. Dung ${ }^{\mathrm{a}}$, F.M. Rombouts ${ }^{\mathrm{b}}$, M.J.R. Nout ${ }^{\mathrm{b}, *}$ \\ a Biotechnology Research and Development Institute, Can Tho University, Can Tho City, Vietnam \\ ${ }^{\mathrm{b}}$ Laboratory of Food Microbiology, Department of Agrotechnology and Food Sciences, Wageningen University, The Netherlands
}

Received 20 January 2005; received in revised form 23 April 2005; accepted 18 May 2005

Available online 1 July 2005

\begin{abstract}
The role of starch-degrading mycelial fungi, and the alcohol production and ethanol tolerance of the yeasts isolated from selected Vietnamese traditional rice wine starters were examined, and optimum conditions for these essential steps in rice wine fermentation were determined. Of pure isolates from Vietnamese rice wine starters, mould strains identified as Amylomyces rouxii, Amylomyces aff. rouxii, Rhizopus oligosporus and Rhizopus oryzae, were superior in starch degradation, glucose production and amyloglucosidase activity during the saccharification of purple glutinous rice. A. rouxii was able to produce up to $25 \% \mathrm{w} / \mathrm{w}$ glucose with an amyloglucosidase activity up to $0.6 \mathrm{U} \mathrm{g}^{-1}$ of fermented moulded mass. Five yeast isolates identified as Saccharomyces cerevisiae were selected for their superior alcohol productivity. They were able to deplete a relatively high initial percentage of glucose $(20 \% \mathrm{w} / \mathrm{v})$, forming $8.8 \% \mathrm{w} / \mathrm{v}$ ethanol. The ethanol tolerance of $S$. cerevisiae in challenge tests was $9-10 \% \mathrm{w} / \mathrm{v}$, and $13.4 \% \mathrm{w} / \mathrm{v}$ as measured in fed-batch fermentations. Optimum conditions for the saccharification were: incubation for $2 \mathrm{~d}$ at $34^{\circ} \mathrm{C}$, of steamed rice inoculated with $5 \log \mathrm{cfu} \mathrm{g}^{-1}$; for the alcoholic fermentation $4 \mathrm{~d}$ at $28.3{ }^{\circ} \mathrm{C}$, of saccharified rice liquid inoculated with $5.5 \log \mathrm{cfu} \mathrm{mL}^{-1}$.

(C) 2005 Elsevier Ltd. All rights reserved.
\end{abstract}

Keywords: Rice wine; Saccharification; Alcoholic fermentation; Fungi; Moulds; Yeasts; Amylomyces; Saccharomyces

\section{Introduction}

In Asian countries, rice wine is a popular alcoholic beverage; e.g. wine from purple glutinous rice (Oryza sativa var. glutinosa) is a well-known and popular traditional product in Vietnam. This beverage has not yet benefitted of scientific research and development efforts; nevertheless, it is particularly interesting because of its sherry-like taste and flavour, and its attractive brown-red colour. Its production is a source of income for farmer families. It is manufactured under non-sterile conditions at home-scale, using traditional solid-state starters in tablet form. This practice produces low yields of wine of variable quality. Whereas wine producers are aware that the choice of starter tablets influences the

\footnotetext{
${ }^{*}$ Corresponding author. Tel.: + 31317482834 ; fax: +31317484978 .

E-mail address: rob.nout@wur.nl (M.J.R. Nout).
}

yield and quality of wine, there is very limited knowledge about the relation between the way they are prepared, their microbiological composition and their performance as starters. It has been reported elsewhere that moulds present in the starters produce starchdegrading enzymes, whereas yeasts from the same starters convert the sugars into alcohol (Nout and Aidoo, 2002). In the present study, the fungi (moulds and yeasts) from traditional Vietnamese starter tablets receive major attention as they are considered crucial for rice wine manufacture.

The liquefaction and saccharification of rice during aerobic solid-state fermentation results from moulds producing $\alpha$-amylase and amyloglucosidase that degrade rice starch into dextrins and maltose, but mainly into glucose (Crabb, 1999). Zygomycetous moulds are commonly found in Vietnamese rice wine starters (Luong, 1998). The other major conversion involved in 
the preparation of this rice wine is the alcoholic fermentation. Whereas some moulds can ferment sugar into ethanol under anaerobic conditions, yeasts are more efficient fermenters. On the other hand, some yeasts can degrade starch but this trait is not widespread (De Mot and Verachtert, 1987; Laluce et al., 1988). The yeast Saccharomycopsis (Endomycopsis) fibuligera, which is one of the common yeasts present in traditional rice wine starters was reported to have amylolytic activity and some ethanol producing capacity (Limtong et al., 2002). However, the predominant yeasts in alcoholic fermentation belong to the genus Saccharomyces, especially S. cerevisiae (Battcock and Ali, 1993). Ethanol is the major product from this fermentation, but at increasing levels it inhibits the yeast in various ways (Jones, 1989; D'Amore et al., 1990), such as inhibition of cell growth, viability and fermentation activity. Therefore, ethanol tolerance is one of our selection criterion for wine yeasts. Methods that could be used to assay and define ethanol tolerance are, e.g. to monitor the effects of accumulating ethanol in batch culture growth, fermentative capacity, and cell viability. Tolerance could also be defined as the maximum level of ethanol produced.

With the ultimate aim to upgrade the traditional starter tablet technology for wine-making in the Mekong Delta area in Vietnam, preliminary screening experiments of traditional starter tablets were carried out (Dung et al., unpubl. data). These resulted in a selection of rice wine starters showing strong starch degradation, alcohol production or both. The objectives of the present study were to examine the properties of moulds and yeasts isolated from these selected starters, and to optimize the conditions for starch degradation and alcoholic fermentation.

\section{Materials and methods}

\subsection{Cultures}

A total of 104 isolates, comprising 53 moulds and 51 yeasts, had been isolated from six Vietnamese traditional rice wine fermentation starters. These starters had been selected from a collection of 29 traditional starters, using the following criteria: ability to liquefy cooked rice, production of high ethanol levels, and of attractive flavour and colour in rice wine. Yeast cultures were grown at $30^{\circ} \mathrm{C}$ for $2 \mathrm{~d}$ on Malt Extract Agar (MEA, Oxoid, CM59); mould cultures were grown for $5 \mathrm{~d}$ at $30{ }^{\circ} \mathrm{C}$ on the same medium. Grown cultures were maintained at $4{ }^{\circ} \mathrm{C}$.

Some of the highly performing moulds and yeasts were identified (Yarrow, 1998). These included Amylomyces rouxii (strains no. 6.9, 20.3, 20.7; deposited as CBS strains no. 111759, 111757, 111758, respectively);
Amylomyces aff. rouxii (an atypical form of $A$. rouxii, strain no. 20.2, deposited as CBS strain no. 111760); Rhizopus oligosporus (strain no. 6.5); and Rhizopus oryzae (including strains no. 15.2, 15.4, 15.5). The best yeasts were identified as Saccharomyces cerevisiae (strains no. 2.1, 15.7 (deposited as LU strains no. 1250, 1252 respectively), 20.4, 23.9, 29.2). CBS = CentraalBureau voor Schimmelcultures, Utrecht, The Netherlands; LU $=$ Wageningen University, Wageningen, The Netherlands.

\subsection{Preparation of inoculum}

A suspension of the growing microbial cells or spores was made by adding $5 \mathrm{~mL}$ of sterile physiological salt solution $(0.85 \% \mathrm{w} / \mathrm{v} \mathrm{NaCl})$ onto each slant. The fungal spores and the yeast cells were scraped off the agar by means of an inoculation loop.

\subsection{Preparation of saccharified purple glutinous rice liquid}

Saccharified purple glutinous rice liquid was prepared as follows: $50 \mathrm{~g}$ of purple glutinous rice and $60 \mathrm{~mL}$ of distilled water in a $250 \mathrm{~mL}$ conical flask covered by a cotton plug, were soaked for $4 \mathrm{~h}$ at $22^{\circ} \mathrm{C}$. After soaking, the mixture was steamed in an autoclave for $1 \mathrm{~h}$ at $100{ }^{\circ} \mathrm{C}$. The steamed rice was cooled to $35-40{ }^{\circ} \mathrm{C}$, then inoculated with $A$. rouxii (strain 20.3) $\left(5 \operatorname{log~cfu~g}^{-1}\right.$ rice) and mixed well. After incubation for $3 \mathrm{~d}$ at $30^{\circ} \mathrm{C}$, the saccharified mass was centrifuged and the supernatant collected. The saccharified liquid was standardized to $20^{\circ}$ Brix $(\% \mathrm{w} / \mathrm{w}$ of dissolved solids $)$ using a refractometer (FG102/112, Euromex-Holland) by adding sterile water.

\subsection{Screening test for starch degradation}

The starch agar medium contained $0.5 \% \mathrm{w} / \mathrm{v}$ of glutinous rice flour, $0.1 \% \mathrm{w} / \mathrm{v}$ of peptone (Oxoid, L34) and $1.5 \% \mathrm{w} / \mathrm{v}$ of agar (Oxoid, L13). A piece of mould pure culture was transferred onto the centre of a plate of starch agar medium by means of an inoculating needle and incubated at $30^{\circ} \mathrm{C}$ for $48 \mathrm{~h}$. Visualization of starch degradation was done by flooding with a $0.25 \%$ iodine solution. Clearing of the typically blue coloration of the starch with iodine indicated starch degradation.

\subsection{Procedure of saccharification test}

Steamed rice (see Section 2.3) was cooled to $35-40{ }^{\circ} \mathrm{C}$, then inoculated and mixed well with pure mould cultures, which had been grown for $5 \mathrm{~d}$ at $30^{\circ} \mathrm{C}$ on a slant of MEA and suspended in a certain volume of sterile physiological salt solution to obtain a final level 
of $10^{6}$ spores $\mathrm{g}^{-1}$ of steamed rice. The inoculated rice was incubated for $4 \mathrm{~d}$ at $30^{\circ} \mathrm{C}$ and then harvested for further analysis.

\subsection{Screening for alcoholic fermentation and fermentation rate}

The procedure for screening was as follows: $50 \mathrm{~mL}$ of saccharified purple glutinous rice liquid at $20^{\circ}$ Brix in a $250 \mathrm{~mL}$ conical flask covered by a cotton plug was sterilized at $115^{\circ} \mathrm{C}$ for $10 \mathrm{~min}$. The sterile liquid was inoculated $\left(10^{6}\right.$ yeast cells $\mathrm{mL}^{-1}$ rice liquid) and mixed well. The inoculated liquid was incubated at $30^{\circ} \mathrm{C}$ for $5 \mathrm{~d}$ under a water lock. At the end of the fermentation, ethanol content, residual glucose and $\mathrm{pH}$ were measured.

The fermentation rate was monitored by measuring the rate of gas discharges from a water lock, and glucose consumption and ethanol production were measured in samples taken at $6 \mathrm{~h}$ intervals during the incubation.

\subsection{Tolerance to gradual accumulation of ethanol in a fed-batch fermentation}

The ability of yeasts to produce ethanol under conditions of unlimited but not excessive glucose supply was tested in a fed-batch fermentation. As soon as the gas production rate decreased, sterile glucose solution was supplemented by adding $5 \mathrm{~mL}$ of filter-sterilized stock glucose solution $50 \% \mathrm{w} / \mathrm{v}$ to $50 \mathrm{~mL}$ of fermenting saccharified liquid. Supplementation was continued until the yeasts failed to resume gas production. To determine the levels of glucose and ethanol, for each treatment $0.2 \mathrm{~mL}$ of sample was taken aseptically and immediately after inoculation, just before adding glucose, and further at time intervals of $5 \mathrm{~d}$ up till 1 month of fermentation. Because of the gradually increasing volume of medium, all analyses (glucose supplied, remaining glucose and ethanol formed) were expressed in absolute quantities (g). The amount of $0.2 \mathrm{~mL}$ for sampling was negligibly small, therefore the total volume reduction due to sampling was not considered in the calculation. The gas production (discharge rate) was recorded daily.

\subsection{Challenge tests with ethanol-supplemented rice liquid}

Pure ethanol was added to saccharified rice liquid at levels of $0 \%, 5 \%, 10 \%, 15 \%$ and $20 \% \mathrm{w} / \mathrm{v}$, and this was inoculated with $10^{4}$ yeast cells $\mathrm{mL}^{-1}$ (microscopic count). Numbers of viable yeast cells at start and after $3 \mathrm{~d}$ of fermentation at $30^{\circ} \mathrm{C}$ were measured, by plate counting on MEA.

\subsection{Analytical methods}

The $\mathrm{pH}$ was measured with a digital $\mathrm{pH}$ meter WTW $\mathrm{pH}$ 525. Glucose and ethanol were determined by HPLC, using an Aminex HPX-87 H Ion Exclusion Column $300 \mathrm{~mm} \times 7.8 \mathrm{~mm}$ (BIO-RAD, Thermo Separation Products Inc. USA). Amyloglucosidase was assayed by using a Megazyme (RAMGR3) test kit of $p$ nitrophenyl- $\beta$-maltoside (McCleary et al., 1991).

\subsection{Statistical analysis}

Experimental data were statistically analysed using Statgraphics Plus Version 5, Manugistics, Inc., Rockville, USA and the software of the General Algebraic Modeling System (GAMS), Washington, DC, USA.

\subsection{Mould growth and starch degrading activity}

A factorial design ( 3 factors at 3 levels) was used: spore inoculum (using a spore suspension of $10^{8}$ spores $\mathrm{mL}^{-1}$ by microscopic count, three levels of spore inoculation were made at 4,5 , and $6 \log \mathrm{cfug}^{-1}$ of steamed rice), incubation time $(2,3$ and $4 \mathrm{~d})$ and incubation temperature $\left(20,30\right.$ and $\left.40^{\circ} \mathrm{C}\right)$. Each treatment had duplicates.

\subsection{Fermentation capacity}

A factorial design ( 3 factors at 3 levels) was used: inoculum rate (using a yeast suspension of $10^{8}$ cells $\mathrm{mL}^{-1}$ by microscopic count, three levels of yeast inoculation were made at 4,5 , and $6 \log \mathrm{cfu} \mathrm{mL}^{-1}$ of saccharified liquid, incubation time (2, 3 and $4 \mathrm{~d})$ and incubation temperature $\left(20,30\right.$ and $\left.40^{\circ} \mathrm{C}\right)$. Each treatment had duplicates.

\section{Results and discussion}

\subsection{Liquefaction of gelatinized purple glutinous rice starch by mycelial fungi}

The hydrolysis of gelatinized rice starch was evaluated by measuring diameters of clearing zones in rice-starch agar. These are presented in Table 1 for the 53 mould isolates tested, in which three categories (very good, medium and poor) were distinguished significantly at the $95 \%$ confidence level. It was observed that although most strains grew very well on glutinous rice-starch agar, this did not imply that they are equally good at starch degradation. However, it could be concluded that all strains that actively degraded starch, always grew well.

From the screening test of the starch degradation, group 1 consisting of eight mould strains (see 
Table 1

Starch degradation by moulds isolated from traditional Vietnamese rice wine starters

\begin{tabular}{lll}
\hline Group of isolates & Number of isolates & $\begin{array}{l}\text { Diameter of clearing } \\
\text { zone }(\mathrm{cm})\end{array}$ \\
\hline Group 1 & 8 & $7.1-9.0^{\mathrm{a}}$ \\
Group 2 & 21 & $5.0-6.3$ \\
Group 3 & 24 & $2.1-4.7$ \\
\hline
\end{tabular}

Moulds were inoculated on glutinous rice starch plates, incubated at $30{ }^{\circ} \mathrm{C}$ for $48 \mathrm{~h}$, and the plates were subsequently flooded with $0.25 \%$ iodine solution.

${ }^{\mathrm{a}}$ values are means of duplicates

Section 2.1) that had been isolated from four different traditional rice wine starters, all having strong starch degrading ability; these strains were studied in more detail for their saccharification.

\subsection{Saccharification of purple glutinous rice starch by mycelial fungi}

Starch saccharification, shown in Table 2, was tested by inoculating pure mould strains into a previously gelatinized glutinous rice mass followed by incubation at $30^{\circ} \mathrm{C}$. All strains except 6.5 (Rhizopus oligosporus), caused a release of free liquid after $1 \mathrm{~d}$ of incubation, which increased with time of incubation. Samples of liquid and solid mass were taken daily and $\mathrm{pH}$, glucose and amyloglucosidase activity were measured.

During the incubation, the $\mathrm{pH}$ rapidly decreased to a range of 4.0-4.7, as compared to a $\mathrm{pH}$ of 6.2 of the uninoculated control. This $\mathrm{pH}$ range is also indicative of the purity of the mould cultures, since in cultures contaminated with (acidifying) bacteria, the $\mathrm{pH}$ usually becomes considerably lower, in the range of $\mathrm{pH} 3.0-3.5$.

Production of glucose levels and of amyloglucosidase activity are also shown. All strains produced the highest glucose levels after $3 \mathrm{~d}$ of incubation. Three groups of moulds, with different levels of glucose production could be distinguished; in the order from high to low levels as follows: group 1 including strains 6.9, 20.3, 20.7 (A. rouxii) and 20.2 (Amylomyces aff. rouxii); group 2 including 15.2, 15.4 and 15.5 ( $R$. oryzae); and group 3 including 6.5 ( $R$. oligosporus). The differences between these three levels were statistically significant at the $95 \%$ confidence level. The highest measured glucose level was $25 \% \mathrm{w} / \mathrm{w}$ of moulded rice mass. There was a good correlation between glucose levels and amyloglucosidase activities. Strains producing high glucose levels also had significantly higher enzyme activities. Thus, as with glucose accumulation, the same three groups can be distinguished by different amyloglucosidase activity. The highest amyloglucosidase activity found was $0.6 \mathrm{U} \mathrm{g}^{-1}$ of moulded rice mass. Strains that gave the

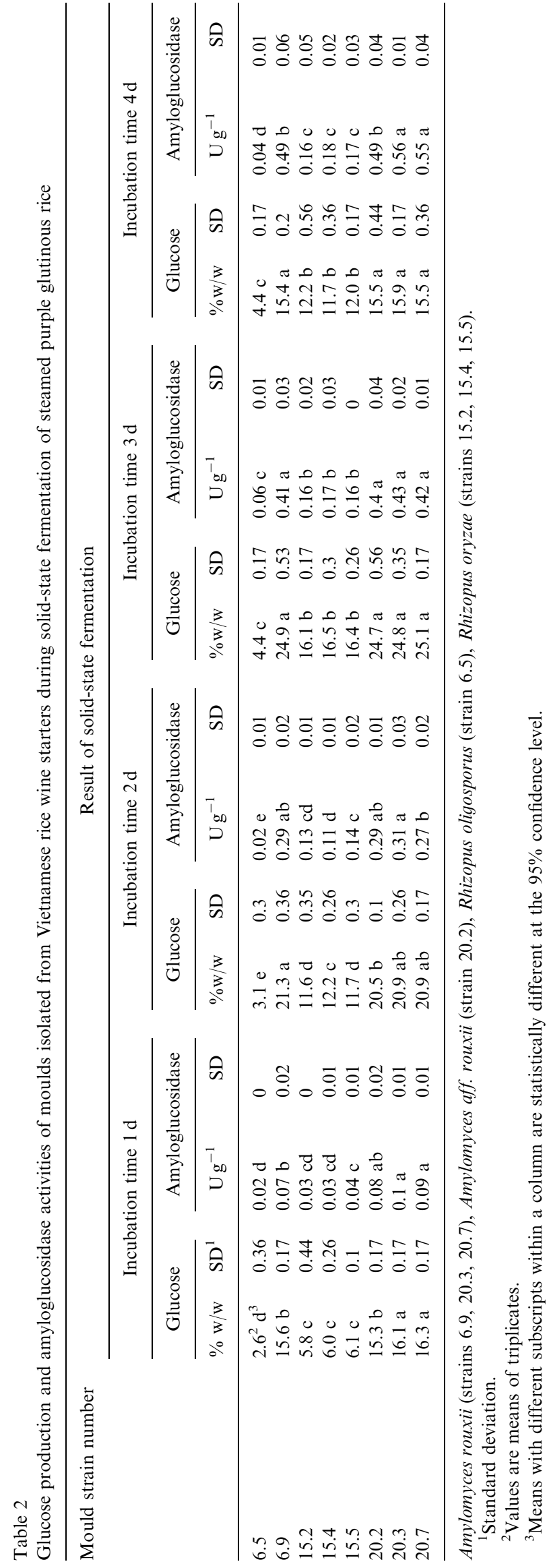


same superior performance in starch degradation and saccharification belonged to the same species, A. rouxii.

However, after $4 \mathrm{~d}$ of incubation, glucose levels decreased whereas amyloglucosidase still continued to increase. This apparent discrepancy can be explained by the consumption of glucose by the moulds.

\subsection{Optimization of glucose accumulation by Amylomyces rouxii}

Because of its powerful glucose production and enzymatic activity, A. rouxii strain 20.3 was selected for the study of factors affecting saccharification performance. According to the statistical design, we used 27 treatments as presented in Table 3 together with the $\mathrm{pH}$, glucose levels and amyloglucosidase activities resulting from the experiment. Combinations producing high glucose levels were in a range of $\mathrm{pH} 4.3-4.8$ and less favourable conditions for glucose accumulation resulted in a $\mathrm{pH}$ range of 5.5-6.2. It was reported earlier (Ellis et al., 1976) that $A$. rouxii is favoured by temperatures around $30^{\circ} \mathrm{C}$ but still shows good growth and enzyme activity at 37 and $40^{\circ} \mathrm{C}$. The final $\mathrm{pH}$ range of approx. 4.0 would also create optimum conditions for its amylolytic enzymes (Underkofler, 1976).

Liquefaction of rice was temperature dependent; whereas at $20^{\circ} \mathrm{C}$ no liquid was formed due to the poor growth during solid-state fermentation, much liquid was produced at 30 and $40{ }^{\circ} \mathrm{C}$ in all cases after $2 \mathrm{~d}$ of incubation. Both glucose and amyloglucosidase levels in liquid (when present) were much higher (even twice in some cases) than those in solid moulded rice mass. This can be explained by the difference in water content of liquid and solid mass. Again, combinations with high glucose levels also had high amyloglucosidase activity. However, at the same favourable incubation temperature, glucose accumulation was significantly influenced by both the incubation time and inoculation level, whereas amyloglucosidase activity was not influenced by inoculation level.

Table 3

Effect of inoculation level and incubation conditions on glucose accumulation by Amylomyces rouxii strain 20.3 during solid-state fermentation

\begin{tabular}{|c|c|c|c|c|c|c|c|c|}
\hline \multirow[t]{3}{*}{ No. } & \multicolumn{3}{|c|}{ Testing factors } & \multicolumn{5}{|c|}{ Result of Solid-State Fermentation } \\
\hline & \multirow{2}{*}{$\begin{array}{l}\text { Incubation } \\
\text { temperature } \\
\left({ }^{\circ} \mathrm{C}\right)\end{array}$} & \multirow{2}{*}{$\begin{array}{l}\text { Incubation } \\
\text { time }(d)\end{array}$} & \multirow{2}{*}{$\begin{array}{l}\text { Inoculation } \\
\text { levels (log } \\
\text { spores } \mathrm{g}^{-1} \text { ) }\end{array}$} & \multirow[b]{2}{*}{$\mathrm{pH}$} & \multicolumn{2}{|c|}{ Glucose } & \multicolumn{2}{|c|}{ Amyloglucosidase } \\
\hline & & & & & Solid $(\% \mathrm{w} / \mathrm{w})$ & Liquid $(\% \mathrm{w} / \mathrm{v})$ & Solid $\left(\mathrm{Ug}^{-1}\right)$ & Liquid $\left(\mathrm{UmL}^{-1}\right)$ \\
\hline 1 & 20 & 2 & 4 & 6.2 & 0.07 & No liquid formed & 0 & No liquid formed \\
\hline 2 & 20 & 2 & 5 & 6.1 & 0.09 & & 0 & \\
\hline 3 & 20 & 2 & 6 & 5.9 & 0.16 & & 0 & \\
\hline 4 & 20 & 3 & 4 & 6.0 & 0.23 & & 0.05 & \\
\hline 5 & 20 & 3 & 5 & 5.8 & 0.24 & & 0.05 & \\
\hline 6 & 20 & 3 & 6 & 5.7 & 0.7 & & 0.06 & \\
\hline 7 & 20 & 4 & 4 & 5.8 & 0.8 & & 0.06 & \\
\hline 8 & 20 & 4 & 5 & 5.6 & 2.5 & & 0.06 & \\
\hline 9 & 20 & 4 & 6 & 5.5 & 2.8 & & 0.06 & \\
\hline 10 & 30 & 2 & 4 & 4.6 & 15.1 & 28.3 & 0.34 & 0.55 \\
\hline 11 & 30 & 2 & 5 & 4.5 & 21.9 & 34.8 & 0.36 & 0.55 \\
\hline 12 & 30 & 2 & 6 & 4.5 & 14.4 & 28 & 0.32 & 0.54 \\
\hline 13 & 30 & 3 & 4 & 4.6 & 15.9 & 27.5 & 0.35 & 0.54 \\
\hline 14 & 30 & 3 & 5 & 4.3 & 20 & 33 & 0.37 & 0.59 \\
\hline 15 & 30 & 3 & 6 & 4.4 & 14.6 & 26.1 & 0.32 & 0.54 \\
\hline 16 & 30 & 4 & 4 & 4.4 & 13.9 & 24.2 & 0.34 & 0.68 \\
\hline 17 & 30 & 4 & 5 & 4.6 & 14.5 & 30.6 & 0.36 & 0.67 \\
\hline 18 & 30 & 4 & 6 & 4.7 & 12.1 & 25.7 & 0.34 & 0.65 \\
\hline 19 & 40 & 2 & 4 & 4.7 & 13.4 & 23.4 & 0.17 & 0.37 \\
\hline 20 & 40 & 2 & 5 & 4.6 & 16.2 & 30.9 & 0.18 & 0.38 \\
\hline 21 & 40 & 2 & 6 & 4.6 & 12.1 & 26.6 & 0.18 & 0.35 \\
\hline 22 & 40 & 3 & 4 & 4.6 & 13 & 28 & 0.28 & 0.58 \\
\hline 23 & 40 & 3 & 5 & 4.6 & 14.1 & 30.3 & 0.27 & 0.57 \\
\hline 24 & 40 & 3 & 6 & 4.7 & 13.9 & 27.2 & 0.27 & 0.56 \\
\hline 25 & 40 & 4 & 4 & 4.8 & 13.2 & 25 & 0.24 & 0.49 \\
\hline 26 & 40 & 4 & 5 & 4.8 & 15.5 & 27.4 & 0.23 & 0.44 \\
\hline 27 & 40 & 4 & 6 & 4.8 & 14.2 & 25.6 & 0.24 & 0.5 \\
\hline
\end{tabular}

The mould spore suspensions were inoculated at the indicated levels into gelatinized purple glutinous rice in conical flasks with a cotton plug, and incubated at the indicated time-temperature combinations, after which samples of saccharified rice (solid moulded mass including liquid and only liquid when present) were analysed for $\mathrm{pH}$, glucose contents and amyloglucosidase activity. In each treatment values are means of duplicates. 
Fig. 1 presents a surface plot based on the statistical analysis of the data presented in Table 3. Optimum conditions are a combination of incubation temperature of $34{ }^{\circ} \mathrm{C}$, incubation time of $2 \mathrm{~d}$ and inoculation level of $5 \log \mathrm{cfu} \mathrm{g}^{-1}$ of steamed rice. The statistical analysis of the variability of glucose production distinguishing the contributions due to the three above-mentioned factors showed that because of $p$-values less than 0.05 , incubation temperature and inoculation level had a statistically significant effect on glucose accumulation ( $95 \%$ confidence level).

\subsection{Screening of yeasts for alcoholic fermentation}

The fermentative capacity of the 51 yeast isolates studied, is summarized in Table 4. Three groups of yeasts, producing different levels of ethanol could be distinguished at a statistical significance of $95 \%$ confidence. Six isolates, belonging to groups 1 and 2 originated from the same rice wine starter whereas the remainder of 45 isolates in group 3 came from five other starters.

After $1 \mathrm{~d}$ of fermentation, group 3 showed clear signs (gas, foam) of fermentation, and after $4 \mathrm{~d}$ the fermentation had stopped so the final analysis was done after $5 \mathrm{~d}$. In groups 1 and 2, the lesser extent of fermentation left approx. $6-8 \% \mathrm{w} / \mathrm{v}$ residual glucose with relatively low

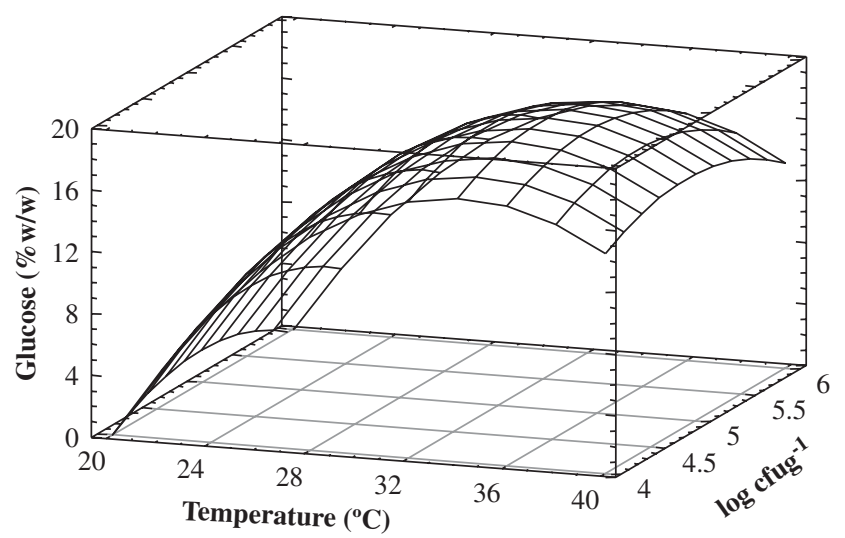

Fig. 1. Effect of incubation temperature and inoculation level on concentration of glucose accumulated by Amylomyces rouxii strain 20.3 (at the optimum incubation period of $2 \mathrm{~d}$ ). ethanol contents of $4-5.9 \% \mathrm{w} / \mathrm{v}$ in comparison to $8.2-8.8 \% \mathrm{w} / \mathrm{v}$ in group 3 . The final products of group 3 had a strong alcoholic and weak fruity flavour whereas the flavours of samples in groups 1 and 2 were weakly alcoholic and slightly sour, which might correspond with their lower $\mathrm{pH}$ values. Possibly, isolates of groups 1 and 2 are more sensitive to alcohol, or might have oxidized some sugar into, e.g. gluconic or acetic acid resulting in low $\mathrm{pH}$; on the other hand, isolates of group 3 are strongly fermentative yeasts.

Five randomly selected isolates from group 3 were all identified as $S$. cerevisiae (see Section 2.1). Ecological studies described several other yeast species in rice wine starters, but apparently our selection of strong fermenting yeasts resulted in $S$. cerevisiae only. This species is predominant in most alcoholic fermented beverages. The five $S$. cerevisiae strains were examined further separately, since they had been isolated from different rice wine starters. Fig. 2 shows the fermentation curve of $S$. cerevisiae strain 2.1. A strong increase of gas production rate was observed after $24 \mathrm{~h}$ of fermentation followed by a significant decrease after $60 \mathrm{~h}$ and the depletion of a relatively high initial concentration of glucose.

\subsection{Tolerance to ethanol accumulation in a fed-batch fermentation}

The ethanol and substrate (sugar) concentrations interact to determine the inhibitory effect of ethanol. This effect has been explained in terms of osmolality.

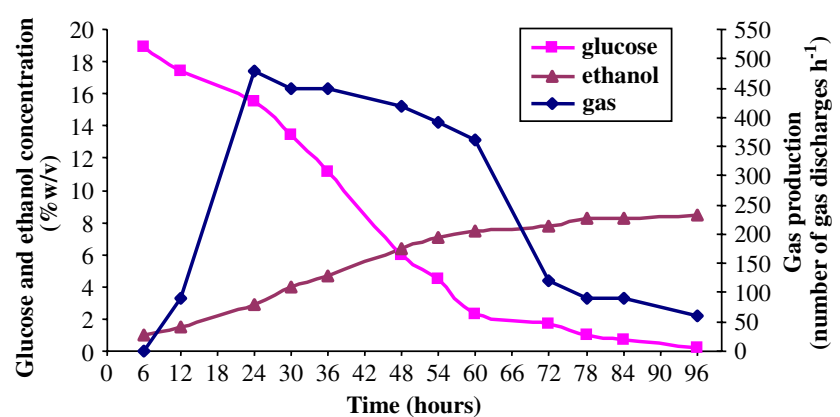

Fig. 2. Glucose consumption, ethanol and gas production by Saccharomyces cerevisiae (strain no. 2.1) incubated at $30^{\circ} \mathrm{C}$

Table 4

Fermentation of saccharified rice liquid by yeasts isolated from traditional Vietnamese rice wine starters ${ }^{\text {a }}$

\begin{tabular}{llll}
\hline Group of strains (number of isolates) & Alcohol content $(\% \mathrm{w} / \mathrm{v})$ & Residual glucose content $(\% \mathrm{w} / \mathrm{v})$ & $\mathrm{pH}$ \\
\hline Group 1 (1 isolate) & 4.3 & 8 & 3.0 \\
Group 2 (5 isolates) & $5.2-5.9$ & $6-8$ & $3.0-3.2$ \\
Group 3 (45 isolates) & $8.2-8.8$ & 0 & $3.7-3.9$ \\
\hline
\end{tabular}

\footnotetext{
${ }^{\text {a }}$ Fermentation tests were carried out on saccharified purple glutinous rice liquid, standardized at $20^{\circ}$ Brix, in conical flasks with water locks.
} Analysis was done after $5 \mathrm{~d}$ of incubation at $30^{\circ} \mathrm{C}$. 
With an increase in the ethanol content of the medium, yeast viability and fermentative ability decrease due to, among other factors, the increase of intracellular ethanol to toxic levels (D'Amore et al., 1990). In order to maintain cell viability and continued ethanol production from maximum amounts of sugar, and simultaneously keep the osmotic effect of the substrate as low as possible, fed-batch or infusion-feeding conditions during fermentation can be used.

In the present experiment, the ethanol tolerance of yeasts was evaluated in a fed-batch experiment under conditions where glucose was not limiting. The time points at which glucose was added were after 2, 4, 6, 9 and $11 \mathrm{~d}$ of fermentation as indicated in Fig. 3. The last supplement of glucose was at $11 \mathrm{~d}$ of fermentation, after which no increase of gas production rate was observed anymore. This indicated that beyond $11 \mathrm{~d}$ of fermentation, newly added glucose did not result in renewed fermentation activity, and that the fermentation rate was now limited by other factors than glucose, hypothetically by the high concentration of accumulated ethanol.

The changes of gas production that were observed up to $15 \mathrm{~d}$ of fermentation are shown in Fig. 3. Until $11 \mathrm{~d}$, the increased gas production after each glucose addition was statistically significant at $95 \%$ confidence level. Although glucose supplementation was stopped after $11 \mathrm{~d}$, the fermentation was allowed to continue and samples for glucose and ethanol determination were taken at time intervals of $5 \mathrm{~d}$ up till 1 month of fermentation. Similar as for gas production, glucose and ethanol analyses (Fig. 4) showed that all five yeast isolates again performed very similar. Yeasts consumed the supplemented glucose for ethanol production very well up to $11 \mathrm{~d}$ of fermentation time, thereby gradually increasing extracellular ethanol levels. However, after this period some small variations of glucose and ethanol levels were observed. Compared with $11 \mathrm{~d}$, the glucose consumed was significantly higher $(95 \%$ confidence level) after $14 \mathrm{~d}$ of fermentation but the ethanol levels did not change. But later at $19 \mathrm{~d}$ of fermentation, the ethanol level was again significantly ( $95 \%$ confidence level) higher and remained stable until the end ( $29 \mathrm{~d})$.

The ethanol yield was used as an indicator to express the capacity to consume glucose and produce ethanol, and was calculated as ( $\mathrm{mol}$ ethanol produced $/ \mathrm{mol}$ glucose consumed) $\times 50(\%)$, with a theoretical maximum of $100 \%$. Fig. 4 shows the similar performance of the five $S$. cerevisiae strains during the fed-batch fermentation. In $50 \mathrm{~mL}$ of saccharified liquid at $20^{\circ}$ Brix, the initial glucose level was $10.5 \mathrm{~g}$. The samplings for analysis were done at $0,4,6,9,11,14,19,24$ and $29 \mathrm{~d}$ of fermentation. The glucose supplementation yielded detectable fermentation response up to the fourth addition (Fig. 3, 11d). During the fed-batch fermentation the yield of fermentation of the five yeast isolates was very similar and varied with time between $84 \%$ and $98 \%$. The last (fifth) supplement of glucose did not

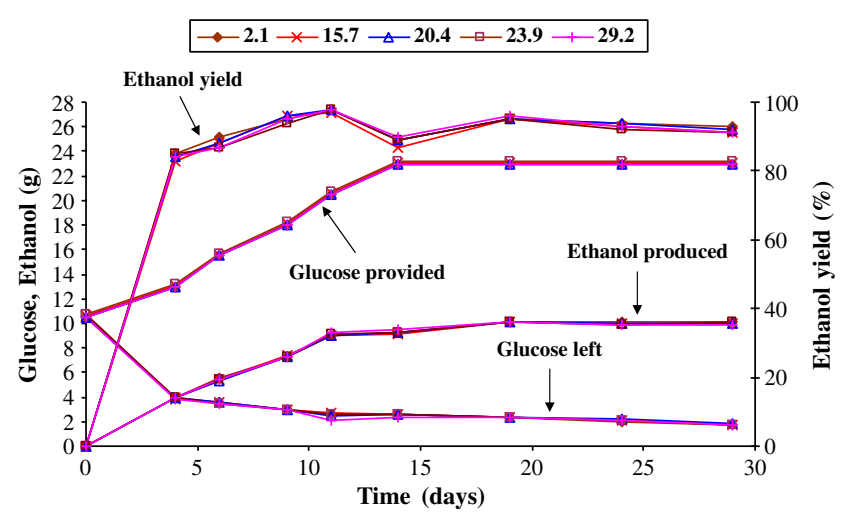

Fig. 4. The performance of five Saccharomyces cerevisiae strains in fed-batch fermentation.

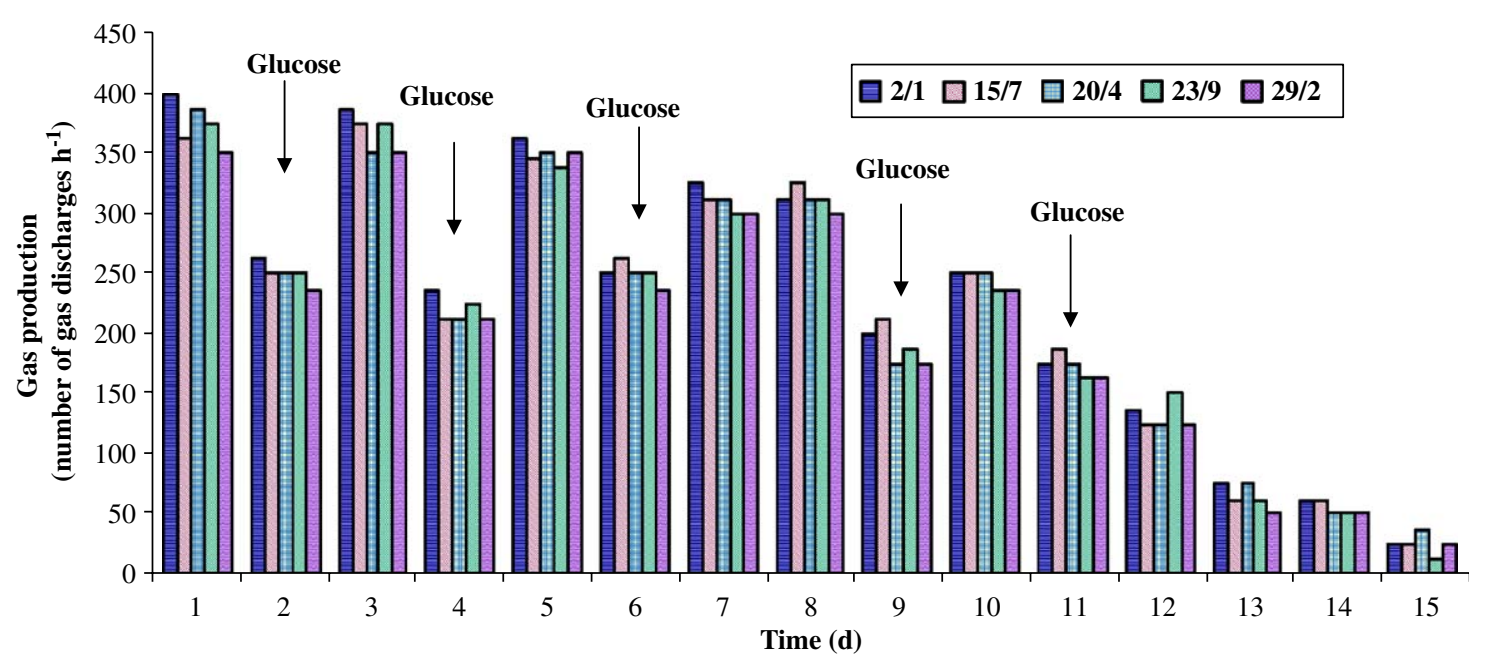

Fig. 3. Gas production rate of five strains $(2.1,15.7,20.4,23.9,29.2)$ of Saccharomyces cerevisiae in a fed-batch fermentation. 
immediately result in increasing fermentation activity, until after 1 week later, a delay presumably needed to restore their fermentation capacity. The fermentation yield then slightly decreased until the last sampling. Glucose supplementation, by five consecutive doses of $5 \mathrm{~mL}$ stock glucose solution $(50 \% \mathrm{w} / \mathrm{v})$, increased the original volume of saccharified liquid from 50 to $75 \mathrm{~mL}$. The maximum ethanol level found was $10.1 \mathrm{~g}$ (corresponding to $13.4 \% \mathrm{w} / \mathrm{v}$ ) whereas a small amount of residual glucose remained $(2.3 \mathrm{~g})$. From this approach we estimate the ethanol tolerance at $13.4 \% \mathrm{w} / \mathrm{v}$.

\subsection{Tolerance to ethanol present in liquid medium (challenge test)}

In this challenge test (see materials and methods), numbers of viable yeast cells at the start and after $3 \mathrm{~d}$ of fermentation at $30^{\circ} \mathrm{C}$ were determined by plate counting and were reported as $\log \mathrm{cfu} \mathrm{mL}^{-1}$ (Fig. 5). Yeasts grew well in medium containing $0 \%$ or $5 \% \mathrm{w} / \mathrm{v}$ ethanol, resulting in higher levels of viable yeast cells compared with the non-incubated control. However, levels of yeasts lower than the inoculation level were found from $10 \% \mathrm{w} / \mathrm{v}$ up to $20 \% \mathrm{w} / \mathrm{v}$ ethanol. When we would define the ethanol tolerance as the level where yeast levels are static, it could be concluded from Fig. 5 that the ethanol tolerance of the yeasts tested was approximately $9-10 \%$ $\mathrm{w} / \mathrm{v}$. This is considerably lower than observed in the fedbatch experiment (approx. 13.4\% w/v). This difference might be explained by the different way of exposure to ethanol: either gradually in the fed-batch fermentation, or instantaneously in the challenge test. Moreover, in the challenge test the yeasts will also produce some ethanol which will increase their stress.

\subsection{Effect of inoculation and incubation conditions on ethanol production by Saccharomyces cerevisiae}

Strain 2.1, one of the five strains of $S$. cerevisiae that showed identical high alcohol production and ethanol

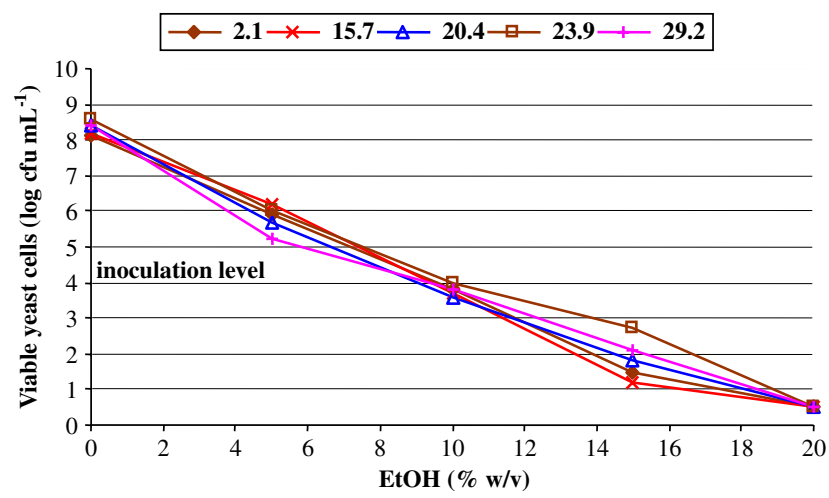

Fig. 5. Growth and decline of five strains of Saccharomyces cerevisiae exposed to various concentrations of ethanol. tolerance, was selected as representative for this experiment. The statistical design involved 27 treatments as outlined in Table 5 .

Table 5 shows that the major factors affecting the alcoholic fermentation were the incubation temperature and time. Only at $30{ }^{\circ} \mathrm{C}$, the fermentation could be completed within $4 \mathrm{~d}$ with a depletion of glucose and the attainment of $\mathrm{pH}$ within the range 3.7-3.9. These $\mathrm{pH}$ changes were not accidental, i.e. caused by bacterial contaminations but should be attributed to the formation of acidic co-metabolites. As a result, the highest ethanol levels were reached at this temperature, and this was achieved slightly faster with higher inoculation levels. At $20^{\circ} \mathrm{C}$ as well as $40^{\circ} \mathrm{C}$, the fermentation was considerably slower as demonstrated by the rates of glucose consumption and ethanol production. Interestingly at $20^{\circ} \mathrm{C}$, higher inoculum rates result in faster glucose consumption whereas the opposite was observed at $40{ }^{\circ} \mathrm{C}$. Judging from this opposite effect of inoculation rate at these temperatures, it is probable that combined effects of temperature-dependent growth rate and ethanol stress have different outcomes at temperatures higher or lower than $T_{\text {opt }}$. This may also be related to the variable outcome of $\mathrm{pH}$, reflecting different results of metabolic regulation.

Fig. 6 shows a surface plot based on the statistical analysis of the data presented in Table 5. Optimum conditions for ethanol production were a combination of incubation temperature of $28.3^{\circ} \mathrm{C}$, incubation time of $4 \mathrm{~d}$ and inoculation level of $5.5 \log \mathrm{cfumL}^{-1}$ of saccharified liquid. Incubation temperature and time had a statistically significant effect on ethanol production $(95 \%$ confidence level). Provided that the temperature is favourable, the effect of the inoculation level on ethanol production was not significant $(<95 \%$ confidence).

\section{Concluding remarks}

This study addresses the essential role of fungi for the performance of starters for rice wine fermentation. The objective was not an ecological study looking for the occurrence and distribution of all fungi present, but instead it was aimed at maximizing productivity and finding highly productive strains. Therefore, only a limited selection of fungi that showed significant abilities for rice wine production were studied. Significantly different levels of glucose produced and of amyloglucosidase activity were observed among pure isolates of moulds. Isolates identified as A. rouxii, Amylomyces aff. rouxii, $R$. oligosporus and $R$. oryzae were selected because of their strong starch degradation in rice starch agar medium. However, in subsequent starch saccharification trials, four Amylomyces spp. strains produced significantly higher levels of glucose and 
Table 5

Effect of inoculation and incubation conditions on the ethanol production by Saccharomyces cerevisiae (strain 2.1)

\begin{tabular}{|c|c|c|c|c|c|c|}
\hline \multirow[t]{2}{*}{ No. } & \multicolumn{3}{|c|}{ Variables } & \multicolumn{3}{|c|}{ Result of alcoholic fermentation } \\
\hline & $\begin{array}{l}\text { Incubation } \\
\text { temperature }\left({ }^{\circ} \mathrm{C}\right)\end{array}$ & Incubation time $(\mathrm{d})$ & $\begin{array}{l}\text { Inoculation levels } \\
\left(\log \text { cells } \mathrm{mL}^{-1}\right)\end{array}$ & Final $\mathrm{pH}$ & Ethanol $(\% \mathrm{w} / \mathrm{v})$ & Glucose $(\% \mathrm{w} / \mathrm{v})$ \\
\hline 1 & 20 & 2 & 4 & 4.5 & 0.6 & 20.7 \\
\hline 2 & 1 & 1 & 1 & 1 & 1 & 1 \\
\hline 3 & 20 & 2 & 6 & 4.2 & 2.7 & 16.4 \\
\hline 4 & 20 & 3 & 4 & 4.2 & 2.7 & 16.7 \\
\hline 5 & 20 & 3 & 5 & 4.1 & 5.3 & 12.2 \\
\hline 6 & 20 & 3 & 6 & 4.1 & 4.7 & 11.0 \\
\hline 7 & 20 & 4 & 4 & 4.2 & 4.0 & 12.2 \\
\hline 8 & 20 & 4 & 5 & 4.1 & 6.6 & 7.3 \\
\hline 9 & 20 & 4 & 6 & 4.1 & 7.2 & 6.7 \\
\hline 10 & 30 & 2 & 4 & 3.8 & 4.7 & 10.8 \\
\hline 11 & 30 & 2 & 5 & 3.7 & 5.9 & 9.8 \\
\hline 12 & 30 & 2 & 6 & 3.8 & 5.3 & 8.7 \\
\hline 13 & 30 & 3 & 4 & 3.7 & 7.8 & 3.5 \\
\hline 14 & 30 & 3 & 5 & 3.7 & 8.5 & 2.1 \\
\hline 15 & 30 & 3 & 6 & 3.8 & 8.5 & 1.7 \\
\hline 16 & 30 & 4 & 4 & 3.8 & 9.7 & 0.1 \\
\hline 17 & 30 & 4 & 5 & 3.9 & 9.7 & 0 \\
\hline 18 & 30 & 4 & 6 & 3.8 & 9.9 & 0.1 \\
\hline 19 & 40 & 2 & 4 & 3.7 & 2.8 & 15.5 \\
\hline 20 & 40 & 2 & 5 & 4.2 & 2.2 & 18.1 \\
\hline 21 & 40 & 2 & 6 & 4.4 & 1.9 & 18.8 \\
\hline 22 & 40 & 3 & 4 & 3.6 & 5.3 & 10.2 \\
\hline 23 & 40 & 3 & 5 & 4.0 & 3.4 & 13.4 \\
\hline 24 & 40 & 3 & 6 & 4.2 & 2.7 & 15.0 \\
\hline 25 & 40 & 4 & 4 & 3.6 & 5.9 & 8.3 \\
\hline 26 & 40 & 4 & 5 & 3.8 & 4.6 & 10.5 \\
\hline 27 & 40 & 4 & 6 & 4.3 & 4.0 & 13.9 \\
\hline
\end{tabular}

Yeast cells were inoculated at the indicated levels in $100 \mathrm{~mL}$ of saccharified purple glutinous rice liquid at $20^{\circ}$ Brix (approx. at $21.5 \% \mathrm{w} / \mathrm{v}$ of glucose analysed by HPLC) in conical flasks with water locks, incubated at the indicated time-temperature combinations. Samples were analysed for $\mathrm{pH}$, ethanol, and residual glucose contents. In each treatment, values are means of duplicates.

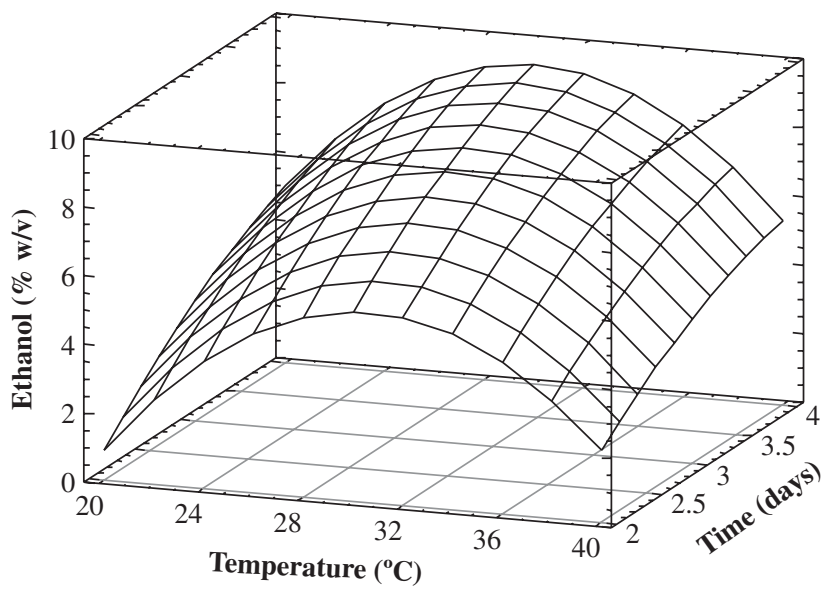

Fig. 6. Effect of incubation temperature and incubation period on concentration of ethanol produced by Saccharomyces cerevisiae strain 2.1 (at the optimum inoculation level of $5.5 \log$ cells $\mathrm{mL}^{-1}$ of saccharified liquid).

amyloglucosidase than Rhizopus spp. strains. This difference can be explained by (a) lower amyloglucosidase activity of Rhizopus spp., and/or (b) higher consumption of glucose by Rhizopus for mycelium production. It should also be noted that successful starch degradation in starch agar is not necessarily a guarantee for good saccharification (Araujo et al., 2004), as the efficiency of saccharification is correlated closely with the glucogenic enzyme system rather than with the activity of $\alpha$-amylase (Underkofler, 1976).

Several categories of yeasts with different ethanol production were distinguished. Five $S$. cerevisiae strains were found to be superior fermenters. It was observed that the pure cultures of moulds and yeasts isolated from selected superior traditional rice wine starters, some even originating from the same starter (such as mould strains 6.5 and 6.9) performed very differently in starch saccharification or in alcoholic fermentation. This confirms that original rice wine starters contain a mix of sometimes excellent but also of less functional strains. The interactions among these micro-organisms, especially between yeasts and moulds, in starch-based starters are of importance for their predominance and performance in wine fermentation. 
We also defined optimum combinations of incubation temperature, incubation time and inoculation level for the glucose-accumulating mould $A$. rouxii and for the superior fermentative and ethanol-tolerant yeast $S$. cerevisiae. Optimum time and temperature conditions for the mould and for the yeast were not the same, indicating that there may be scope to optimize the winemaking process by carrying out subsequent, rather than simultaneous mould and yeast fermentations.

However, in spite of their successive actions of starch degradation and alcoholic fermentation, the mould and yeast strains should also combine well in mixed cultures. It will therefore be necessary to examine the mutual compatibility of moulds and yeasts in order to formulate defined mixed-culture starters. This aspect will require further research.

\section{Acknowledgements}

This research was financially supported by the Ministry of Foreign Affairs, The Hague, The Netherlands and the International Foundation for Science, Stockholm, Sweden (Grant Number E/3322-1).

\section{References}

Araujo, M.A., Cunha, A.M., Mota, M., 2004. Enzymatic degradation of starch-based thermoplastic compounds used in protheses: identification of the degradation products in solution. Biomaterials $25,2687-2693$.
Battcock, M., Ali, S.A., 1993. Fermented fruits and vegetables. FAO Agr. Serv. Bull. 134, 13-28.

Crabb, W.D., 1999. Commodity scale production of sugars from starches. Curr. Opin. Microbiol. 2, 252-256.

D'Amore, T., Panchal, C.J., Russell, I., Stewart, G.G., 1990. A study of ethanol tolerance in yeast. CRC Crit. Rev. Biotechnol. 9, 287-304.

De Mot, R., Verachtert, H., 1987. Some microbiological and biochemical aspects of starch bioconversion by amylolytic yeasts. CRC Crit. Rev. Biotechnol. 5, 259-272.

Ellis, J.J., Rhodes, L.J., Hesseltine, C.W., 1976. The genus Amylomyces. Mycologia 68, 131-143.

Jones, R.P., 1989. Biological principles for the effects of ethanol. Enzyme Microb. Technol. 11, 130-153.

Laluce, C., Bertolini, M.C., Ernandes, J.R., Martini, A.V., Martini, A., 1988. New amylolytic yeast strains for starch and dextrin fermentation. Appl. Environ. Microbiol. 54, 2447-2451.

Limtong, S., Sintara, S., Suwannarit, P., Lotong, N., 2002. Yeast diversity in traditional fermentation starter (Loog-pang). Kasetsart J. (Nat. Sci.) 36, 149-158.

Luong, N.D., 1998. Production of fermented drinks (in Vietnamese). In: Luong, N.D. (Ed.), Microbiological Technology, vol. 3. Technology University, Ho Chi Minh City, Vietnam, pp. 175-188.

McCleary, B.V., Bouhet, F., Driguez, H., 1991. Measurement of amyloglucosidase using $p$-nitrophenyl $\beta$-maltoside as substrate. Biotechnol. Tech. 5, 255-258.

Nout, M.J.R., Aidoo, K.E., 2002. Asian fungal fermented food. In: Osiewacz, H.D. (Ed.), The Mycota, Vol. X "Industrial applications". Springer-Verlag, Berlin, Heidelberg, New York, pp. 23-47.

Underkofler, L.A., 1976. Production of microbial amylolytic enzymes. In: Radley, J.A. (Ed.), Starch production technology. Applied Science Publishers Ltd., London, pp. 295-309.

Yarrow, D., 1998. Methods for the isolation, maintenance and identification of yeasts. In: Kurtzman, C.P., Fell, J.W. (Eds.), The Yeasts, a Taxonomic Study, fourth ed. Elsevier Science B.V., Amsterdam, pp. 77-100. 